\title{
Rumination in PTSD as well as in Traumatized and Non-Traumatized Depressed Patients: A Cross-Sectional Clinical Study
}

\author{
Eva Birrer \\ Klinik fuer Schlafmedizin, Luzern, Switzerland \\ Tanja Michael \\ University of Saarland, Saarbruecken, Germany
}

\begin{abstract}
Background: Although rumination is a key process in the onset and maintenance of depressive symptoms and a powerful predictor of persistent posttraumatic stress disorder (PTSD), little is known about the differences and similarities of rumination in these conditions. Previous research has not always differentiated between rumination and intrusive images. Aims: We sought to systematically evaluate rumination and to gather more information about the content and associated emotions in three patient groups (PTSD, and depressed with and without trauma; $n=65$ ). Furthermore, we examined the interaction between rumination and another predominant intrusive cognition, intrusive image. Method: A multimethod assessment for rumination, including a rumination questionnaire and a rumination log (kept for one week), was employed. Results: Rumination was found to be complex and composed of subcomponents that are similar across the diagnostic groups. Rumination rarely stopped intrusive images and it made the participants feel worse. There were, however, also important differences: in PTSD, rumination always or often triggered intrusive images and the traumatized individuals (PTSD and depressed with trauma) ruminated more than non-traumatized depressed patients. Conclusions: The results corroborate the assumption of rumination being a transdiagnostic process, with similarities but also with important differences across diagnostic groups. Moreover, the findings support recent research on the intricate relationship between different types of intrusive cognitions.
\end{abstract}

Keywords: Posttraumatic Stress Disorder, depression with and without trauma, intrusive images, rumination, triggers.

\section{Introduction}

The human mind is capable of sustaining intense focus and shifting thoughts, and yet we can be disturbed by unintended and unwanted intrusive cognitions, such as thoughts and

Reprint requests to Eva Birrer, Klinik fuer Schlafmedizin, St. Anna-Str. 32, 6006 Luzern, Switzerland. E-mail: birrer@ksm.ch 
images, which interrupt our ongoing activities and redirect attentional resources. Previous research has shown that unwanted intrusive cognitions are a prominent feature of many clinical disorders, including posttraumatic stress disorder (PTSD) and depression, and has suggested these cognitions are transdiagnostic phenomena (e.g. Brewin, Gregory, Lipton and Burgess, 2010; Michael and Ehlers, 2007; Michael, Halligan, Clark and Ehlers, 2007; Michael, Ehlers and Halligan, 2005a; Clark, 2005). Harvey, Watkins, Mansell and Shafran (2004) showed the feasibility and benefits of shifting the perspective away from a "disorder focus" and towards elucidating the common mechanisms, for example, in memory and cognition that appear across disorders - that is, towards a transdiagnostic perspective. Yet research on intrusive thoughts has not always differentiated between the different forms of intrusive cognitive activities, which prevents a clear identification and comparison of these cognitions across diagnostic groups. Furthermore, as cognitive therapy is developing in new directions by emphasizing metacognitive interventions (which try to change an individual's relationship to the intrusive thought rather than directly challenging the thought content, e.g. Hayes, Strosahl and Wilson, 1999; Hayes, Luoma, Bond, Masuda and Lillis, 2006; Segal, Williams and Teasdale, 2002; Wells, 2000; Wells and Sembi, 2004; Wells and Papageorgiou, 2004) it is of particular importance to identify those different types of unwanted intrusive cognitions.

As mentioned above, there are different broad categories of intrusive cognitive activities (Clark and Rhyno, 2005). Most researchers agree that "rumination", a form of verbal cognitive activity that intrudes into consciousness, plays an important role in both depression and PTSD. Rumination is commonly defined as repetitive, cyclical, self-focused, and uncontrollable negative thinking about past negative experiences and/or negative mood that can be cued by an external event or a prior thought (e.g. Nolen-Hoeksema, 1991; Papageorgiou and Wells, 2003; Teasdale, 1999). Rumination is closely related to the concept of worry, which is generally defined as recurring, repetitive, uncontrollable thinking on potential negative life events in the future (Borkovec, Ray and Stober, 1998; Roemer and Borkovec, 1993). Thus, the major difference in definition is that the focus of the thoughts in worry is mainly future oriented, whereas it is mainly past oriented in rumination. As such, worry has typically been examined with respect to anxiety disorders, and rumination with respect to depression. Recent research has shown meaningful overlap and distinct features of both worry and rumination (Fresco, Frankel, Mennin, Turk and Heimberg, 2002; Hong, 2007; McLaughlin, Borkovec and Sibrava, 2007; Muris, Roelofs, Meesters and Boomsma, 2004; Segerstrom, Tsao, Alden and Craske, 2000; Watkins, 2004).

In depression, rumination is a key process at the onset of low mood and in the maintenance of depressive symptoms (Kuehner and Weber, 1999; Nolen-Hoeksema, 1991, 2000; NolenHoeksema, Parker and Larson, 1994; Singer and Dobson, 2007). Rumination deteriorates mood, is related to poor problem solving (Donaldson and Lam, 2004), leads to more negative future thinking and negative cognitive biases (Lavender and Watkins, 2004), and maintains over-general autobiographical memory in depressed patients (Watkins and Teasdale, 2001; Watkins, Teasdale and Williams, 2000).

Although rumination has been examined less often with respect to PTSD, a number of studies have shown that it is a powerful predictor of persistent PTSD (Clohessy and Ehlers, 1999; Ehlers, Mayou and Bryant, 1998; Murray, Ehlers and Mayou, 2002; Steil and Ehlers, 2000). Certain characteristics of rumination, such as compulsion to continue ruminating, occurrence of unproductive thoughts, and "why" and "what-if" types of questions, as well as 
negative emotions before and after rumination, have been significantly associated with PTSD, concurrently and prospectively (Michael et al., 2007). Rumination also seems to be a trigger of intrusive memories (Birrer, Michael and Munsch, 2007) and is used as a strategy to cope with intrusive memories (Michael et al., 2007).

Another form of cognitive activity occurs as "intrusive images". These are typically represented as visual scenes, although other sensory modalities can occur. Intrusive images have been repeatedly studied in individuals with PTSD (i.e. Reynolds and Brewin, 1999; Ehlers, Hackmann and Michael, 2004; Michael, Ehlers, Halligan and Clark, 2005b) as they are a distinctive feature of this disturbance, and with increasing interest in other psychopathologies (for a review see Holmes and Hackmann, 2004), including depression (Brewin, 1998; Brewin, Hunter, Carroll and Tata, 1996; Bywaters, Andrade and Turpin, 2004a, b; Kuyken and Brewin, 1994; Mansell and Lam, 2004; Reynolds and Brewin, 1999).

Behavioural researchers have commenced systematically to investigate the role of these cognitive phenomena in the pathogenesis of clinical disorders such as PTSD and depression. Little is known of the interactions between these different intrusive thoughts. Recent research is just beginning to investigate the interactions among different types of cognitions, revealing the potential catalytic effect of different types of intrusive thoughts and images (Behar, Zuellig and Borkovec, 2005; McLaughlin et al., 2007; Michael et al., 2007; Zetsche, Ehring and Ehlers, 2009).

It may be that the occurrence of an unwanted intrusive image could trigger an episode of depressive rumination. Furthermore, it has been suggested that rumination can function as a form of cognitive avoidance: Dwelling on negative issues related to the trauma but not thinking actively about the traumatic experience itself hinders the emotional processing of the trauma (Foa and Kozak, 1986; Teasdale, 1999). There is some evidence that a strong engagement in "why" and "what-if" types of questions (What would things have been like if only I had done something differently?) also constitutes a form of maladaptive cognitive avoidance (Michael et al., 2005b). The criteria of PTSD, however, include recurrent thoughts of the trauma as an important symptom of this condition. This raises the question of whether rumination after a trauma contains both thoughts about the trauma as well as thoughts on negative issues related to the trauma (including "why" and "what-if" questions). Moreover, given that PTSD patients commonly have many symptoms of depression, one would expect a range of depressive thoughts in rumination.

Thus, one important aim of our study was to gather more information on the content of rumination after experiencing trauma. PTSD and depression often have traumatic experiences in common (Carlier, Voerman and Gersons, 2000; David et al., 1996; Maes, Mylle, Delmeire and Altamura, 2000; Maercker, Michael, Fehm, Becker and Margraf, 2004). Is rumination similar in these conditions and, moreover, what is the interaction between two different types of intrusive cognitions - rumination and intrusive images?

Another question concerns whether rumination differs in individuals who have only experienced everyday critical life events. Not all unusual stress events are traumatic: a distinction is commonly drawn between normative and non-normative events (Schwarzer and Schulz, 2002). Normative episodes refer to events that naturally happen to many individuals at certain times during their lives and are not unexpected, for example, marriage, childbirth, divorce, death of parents, retirement, or loss of a job. In contrast, non-normative events refer to rare or unexpected experiences that are usually thought of as traumatic (Schwarzer and Schulz, 2002). The Diagnostic and Statistical Manual of Mental Disorders (DSM-IV) (American 
Psychiatric Association, 1994) specifies that an event qualifies as a traumatic stressor only if it entails actual or threatened death, serious injury, or a threat to the physical integrity of oneself or others. Following these definitions our study makes a clear distinction between traumatic and non-normative events (so-called critical life events).

We used a multi-method assessment for rumination including a questionnaire and a log that the participants kept for one week:

- To capture detailed data on rumination, including if it occurs, how long it lasts, time of day of occurrence, and any emotions associated with it.

- To collect descriptive information about the content of rumination.

- To examine the level of intrusiveness of rumination, that is, how compelled patients felt to ruminate.

- To investigate the interaction between rumination and intrusive memories.

\section{Method}

\section{Patients}

The participants were 65 patients who volunteered to take part in a study on rumination and intrusive images with and without past traumatic experience (as defined by DSM-IV criteria). The results of the detailed investigation of the intrusive images (assessed by an intrusion questionnaire) of the same sample have been published elsewhere (Birrer et al., 2007). Twenty-six participants had PTSD, 20 had major depression and had suffered a traumatic experience (depressed with trauma), and 19 had major depression with no history of traumatic experience (depressed without trauma). In clinical studies and as experienced in clinical work, PTSD patients usually have co-morbid depression scores similar to those found in our study. Patients in our PTSD group showed depression scores ranging from 11 to 43, which is comparable to other studies and indicates that the great majority were clinically depressed. However, in the present study, five participants with PTSD were not clinically depressed, so we could not name the group "PTSD co-morbid with depression". The ages of the participants ranged from 18 to 82 years (mean age 44.8 years, $S D=13.6$ ). The age ranges in the groups were comparable $\left(F_{2,65}=2.499, p=.09\right)$.

Fisher's exact tests revealed that the groups did not differ with respect to sex $(p=.20)$, nationality $(p=.49)$, religion $(p=.43)$, marital status $(p=.08)$, education $(p=.83)$, or number of previous treatments as inpatients $(p=.34)$ or outpatients $(p=.18)$. The groups however did differ significantly in terms of psychological characteristics: the PTSD group had significantly more posttraumatic symptoms, but they showed depression scores similar to those of the depressed patients with and without trauma (see Table 1).

\section{Measures}

The rumination questionnaire. The rumination questionnaire (see Appendix) was composed as a self-report scale for this study. It is an adapted version of the rumination interview used by Michael et al. (2007). Specifically, the questionnaire asked about the following issues: (1) Occurrence of rumination (answer yes/no); (1a) rumination revolves about the trauma; (1b) rumination revolves about other critical life events; (2) Content and frequency of rumination: (2a) "Why" and "what-if" types of thoughts (e.g. "What could I have done differently before 
Table 1. Psychological characteristics of the participants

\begin{tabular}{|c|c|c|c|c|}
\hline & \multicolumn{3}{|c|}{ Participant group } & \multirow[b]{2}{*}{$\begin{array}{l}\text { Descriptive } \\
\text { test }\end{array}$} \\
\hline & PTSD & $\begin{array}{l}\text { Depressed } \\
\text { with trauma }\end{array}$ & $\begin{array}{l}\text { Depressed } \\
\text { without trauma }\end{array}$ & \\
\hline $\begin{array}{l}\text { Mean PDS } \\
\text { score }(S D)\end{array}$ & $31^{\mathrm{a}}(6.3)$ & $21^{\mathrm{b}}(10.9)$ & & $\begin{array}{l}F_{2,55}=10.313 \\
p<.001\end{array}$ \\
\hline $\begin{array}{l}\text { Mean BDI } \\
\text { score }(S D)\end{array}$ & $19(9.6)$ & $24(8.5)$ & $20(6.7)$ & $\begin{array}{l}F_{2,65}=1.996 \\
p=.145\end{array}$ \\
\hline $\begin{array}{l}\text { Mean DID } \\
\text { score }(S D)\end{array}$ & $22(9.2)$ & $27(9.2)$ & $23(7.2)$ & $\begin{array}{l}F_{2,65}=1.885 \\
p=.160\end{array}$ \\
\hline
\end{tabular}

Note: Numbers with different superscripts differ significantly $(p<.05) . S D=$ Standard deviation, PDS $=$ Posttraumatic Diagnostic Scale, BDI = Beck Depression Inventory, DID $=$ Diagnostic Inventory for Depression

the trauma happened?"; Cronbach's alpha $=.83$, six items); $(2 \mathrm{~b})$ Depressive thoughts (e.g. "About how bad I am"; Cronbach's alpha $=.83$, seven items); $(2 \mathrm{c})$ Thoughts related to the stress event (e.g. "How I felt while experiencing the trauma"; Cronbach's alpha $=.82$, seven items); (3) Level of intrusiveness of rumination: (3a) "I dwell automatically"; "I start to dwell on purpose" and ( $3 b$ ) unproductive thoughts during rumination (e.g. "I seem to be pushed from one topic to the next"; Cronbach's alpha $=.73$, four items); (4) Relationship between rumination and intrusive memories (4a) rumination triggers intrusive memories of the trauma/of critical life event; (4b) rumination stops intrusive memories of the trauma/critical life event. Items in categories 2, 3, and 4 were scored not at all, rarely, sometimes, often, or always.

Items in categories 2 and 3 were factor analyzed to check whether they measured the same concept. For each group of questions, a common factor analysis without rotation was computed. An item was considered to load onto a factor if its factor loading exceeded .40 . Furthermore, items were excluded when the measure of sampling adequacy (MSA), which can be computed for each individual item, was below .60. It was also required that the overall Kayser Meyer-Olkin (KMO) test, which assesses the appropriateness of using factor analysis on the data, yield values greater than .70 (Backhaus, Erichson, Wulff and Weiber, 2000). These criteria led to the exclusion of two items ("I dwell on negative experiences such as separation, loss of work, etc." and "I dwell on things I do not remember").

The rumination log. The rumination log was created for this study. Participants recorded for 7 days at 4 different times of the day if and for how long they had ruminated (not at all, less than $5 \mathrm{~min}$, up to $30 \mathrm{~min}$, up to $1 \mathrm{~h}$, up to $2 \mathrm{~h}$, up to $3 \mathrm{~h}$, up to $4-5 \mathrm{~h}$, up to $6-8$ hours) and how they felt before and after ruminating. Each day was divided into 4 blocks to cover 24 hours: from bedtime in the evening until breakfast in the morning; from breakfast until lunch; from lunch until dinner; from dinner until bedtime. The participants rated how strong their emotions were before and after rumination (on a scale of $0 \%$ to $100 \%$ ): The scale covered sadness, helplessness, empty feelings, guilt, anger, anxiety, shame, hope, calmness, and contentment.

Posttraumatic stress disorder symptoms. PTSD symptoms were assessed with the Posttraumatic Diagnostic Scale (PDS; Foa, Cashman, Jaycox and Perry, 1997). The PDS 
is a standardized self-report measure of PTSD symptoms in line with DSM-IV (American Psychiatric Association, 1994) diagnostic criteria. It shows good agreement with the Structured Clinical Interview for DSM-IV (SCID; $k=.65$, agreement $82 \%$, specificity $=.75$, sensitivity $=.89$; Foa et al., 1997).

The first section of the PDS is a checklist concerning what traumatic events the participant has experienced (it lists several, such as a serious accident, assault, sexual abuse, exposure to war or torture), and the second section asks which traumatic event affected the person most. The third section asks about the objective and subjective threat that was associated with the event. The fourth section examines PTSD symptoms. These are measured with questions on the presence and frequency of each of the PTSD symptoms. Answers are made with a scale ranging from 0 (never) to 3 (five times per week or more). Symptom scores can be totalled to give an overall sum score measuring PTSD severity. The final section of the PDS is concerned with whether the symptoms interfere with the lives of the participants.

The presence/absence of PTSD was determined by assessing whether participants were exposed to a traumatic experience, whether their response involved intense fear, helplessness, or horror, whether they exhibited the required minimum number of symptoms specified in the $D S M-I V$, whether the symptoms were present for at least 1 month, and whether the symptoms caused at least two specific problems in functioning (e.g. ability to work) or affected the overall level of functioning in all areas of life. In addition, a minimum score of 15 on the PDS was required for a positive diagnosis, following the recommendations of Foa (1995).

Depression symptoms. Depression symptoms were assessed with the Beck Depression Inventory (BDI) and with the Diagnostic Inventory for Depression (DID). The BDI (Beck, Ward, Mendelson, Mock and Erbaugh, 1961) is a 21-item self-report measure of depression of established reliability and validity (Beck, Steer and Garbin, 1988). The DID is a standardized self-report scale for diagnosing DSM-IV major depressive disorder (Zimmermann, Coryell, Corenthal and Wilson, 1986).

For practical reasons we could not conduct a structured clinical interview. The sensitivity of the DID is found to be between 73.7 and $83.3 \%$ and the specificity between 93 and 98.2\% according to Zimmerman and Coryell (1987a, b, 1988; validity criterion: Diagnostic Interview Schedule). The DID subscales attain high levels of internal consistency and testretest reliability. Furthermore, the DID correlates highly with interviewer ratings of the severity of depression (Zimmerman, Sheeran and Young, 2004).

To meet the criteria for the diagnosis of depression participants had to have a score of at least 15 on the DID and 11 on the BDI (in accordance with international standards) and including low mood. To meet the criteria for the diagnosis of depression with trauma the participants had to have been exposed to a traumatic event without exhibiting the severity of PTSD-associated symptoms and had to meet the criteria for depression. Depressed participants without traumatic experiences had to show relevant depression scores without being exposed to any traumatic experience during their lifetime.

\section{Procedure}

The participants were recruited from Swiss psychiatric hospitals, private practices, and selfhelp groups for depressed people. Individuals who were interested in participating were given further information and asked for written consent. To assess rumination the participants completed the rumination questionnaire and kept a rumination log for one week. They also 
Table 2. Duration of rumination

\begin{tabular}{lllll}
\hline & \multicolumn{4}{c}{ Participant group } \\
\cline { 2 - 4 } $\begin{array}{l}\text { Duration of rumination } \\
\text { (in hours per 7 days) }\end{array}$ & $\begin{array}{l}\text { PTSD } \\
(n=26)\end{array}$ & $\begin{array}{l}\text { Depressed with } \\
\text { trauma }(n=20)\end{array}$ & $\begin{array}{l}\text { Depressed without } \\
\text { trauma }(n=19)\end{array}$ & Statistics \\
\hline Mean & $5.3^{\mathrm{a}}$ & $5.4^{\mathrm{a}}$ & $2.6^{\mathrm{b}}$ & $\chi^{2}(2)=7.530$ \\
Standard deviation & 4.2 & 4.0 & 2.5 & $p=.2$ \\
\hline
\end{tabular}

Note: Values with different superscripts differ significantly $(p<.05)$.

completed a questionnaire package that assessed depression (BDI, DID), posttraumatic stress symptoms (PDS), and social characteristics. According to their symptoms they were then assigned to one of the three groups (PTSD, depressed with trauma, or depressed without trauma) as described above. In addition to the measures described in the current paper, participants completed another questionnaire concerning the occurrence and experience of intrusive images; the results of which have been presented elsewhere (Birrer et al., 2007).

\section{Data analysis}

Concerning frequencies between diagnostic groups chi-square tests were applied and calculated with exact methods if the assumptions were not met. Between-group differences of continuous data did not meet the assumptions of normal distribution. Therefore the Kruskal-Wallis non-parametric analysis of variance of ranks (Lehmann, 1998) was used. For paired comparisons the Mann-Whitney $U$ test was applied. Friedman's test was used to compare temporal distribution of rumination across the day. Pearson correlations assessed the association between temporal distributions of rumination across the day and insomnia. To assess the change of emotions associated with rumination, Wilcoxon's test was employed. All calculations were made using SPSS version 13.0 (2002) in a strictly descriptive or explorative manner using two-tailed $p$ values and a $p=.05$ significance level.

\section{Results}

All participants of the three groups (PTSD, depressed with trauma, and depressed without trauma) reported dwelling on a traumatic experience or critical life experiences.

\section{Rumination log}

Duration of rumination. According to the rumination log there were significant differences in duration of rumination, as a Kruskal-Wallis analysis reveals (see Table 2). Paired comparisons reveal that there were no differences between the PTSD group and the depressed with trauma group, $U_{(46)}=250.00, p=.4$. However, both the PTSD group, $U_{(46)}=165.00, p=.02$, and the depressed with trauma group, $U_{(39)}=94.00, p=.02$, ruminated more than the depressed without trauma group.

Temporal distribution of rumination. Analyzing at what time of the day the patients ruminated, a Friedman's test showed time preferences for rumination, $\chi^{2}(3)=9.06, p=$ .03 (there were no group differences). The patients ruminated especially at night $(M=1.06 \mathrm{~h}$, 
Table 3. Differences in emotions before and after rumination (mean values are aggregated over the groups ${ }^{\mathrm{a}}$ )

\begin{tabular}{|c|c|c|c|c|}
\hline & $\begin{array}{l}\text { Before } \\
\text { rumination }\end{array}$ & $\begin{array}{l}\text { After } \\
\text { rumination }\end{array}$ & $\begin{array}{l}\text { Difference } \\
\text { d1 }\end{array}$ & Statistics \\
\hline Contentment & 45 & 34 & -13 & $\begin{array}{l}Z=-3.85 \\
p<.001\end{array}$ \\
\hline Calmness & 57 & 45 & -14 & $\begin{array}{l}Z=-3.84 \\
p<.001\end{array}$ \\
\hline Sadness & 71 & 73 & 2 & $\begin{array}{l}Z=-1.85 \\
p=.06\end{array}$ \\
\hline Emptiness & 57 & 58 & 1 & $\begin{array}{l}Z=-0.39 \\
p=.70\end{array}$ \\
\hline Helplessness & 44 & 51 & 7 & $\begin{array}{l}Z=-2.61 \\
p=.009\end{array}$ \\
\hline Anger & 32 & 38 & 6 & $\begin{array}{l}Z=-2.73 \\
p=.006\end{array}$ \\
\hline Guilt feelings & 19 & 23 & 4 & $\begin{array}{l}Z=-2.61 \\
p=.009\end{array}$ \\
\hline
\end{tabular}

${ }^{\text {a }}$ No group differences; feelings rated $0-100$

$S D=1.20 \mathrm{~h})$ and in the afternoon $(M=1.07 \mathrm{~h}, S D=1.10 \mathrm{~h})$ and less in the morning $(M=0.73 \mathrm{~h}, S D=0.95 \mathrm{~h})$ and evening $(M=0.76 \mathrm{~h}, S D=1.10 \mathrm{~h})$. Pearson correlations show a significant association between insomnia assessed by the FDD (item "less sleep") and the preference to ruminate at night $(r=.355 ; p=0.05)$.

Change of emotions associated with rumination. In all the groups (there were no differences) rumination seemed to worsen feelings of anger, helplessness, and guilt and to abate feelings of contentment and calmness. But in all the groups rumination did not affect feelings of emptiness or sadness, as a Wilcoxon's test reveals there was no significant difference before and after rumination (see Table 3).

\section{Rumination questionnaire}

Content of rumination and perceived intrusiveness of ruminations. The frequency of rumination with respect to content and perceived intrusiveness of rumination was analyzed. The groups did not differ with respect to "why" and "what-if" types of thoughts, $\chi^{2}(2)=$ $.217, p=90$, thoughts related to the stress event, $\chi^{2}(2)=.059, p=97$, or depressive thoughts, $\chi^{2}(2)=.185, p=91$ (see Table 4). Participants in all groups experienced their ruminative thoughts as uncontrollable, $\chi^{2}(2)=.272, p=87$. Rumination was never or only sometimes activated on purpose. Ninety-six percent ( 25 of 26) of the participants with PTSD, $95 \%$ (18 of 19) of the depressed participants with trauma, and 90\% (18 of 20) of the depressed participants without trauma stated that rumination was rarely activated on purpose. The groups did not differ [Fisher's exact test, $\left.\chi^{2}(6)=2.008 . p=.959\right]$. However, $92 \%$ (24 of 26) of the participants with PTSD, 90\% (17 out of 19) of the depressed participants with trauma, and $85 \%$ (17 of 19) of the depressed participants without trauma declared that rumination was 
Table 4. Content and intrusiveness of rumination among the three groups of participants: mean, standard deviation (in parentheses) ${ }^{1}$

\begin{tabular}{llll}
\hline & \multicolumn{3}{l}{ Participant group } \\
\cline { 2 - 4 } & PTSD & $\begin{array}{l}\text { Depressed } \\
\text { with trauma }\end{array}$ & $\begin{array}{l}\text { Depressed } \\
\text { without trauma }\end{array}$ \\
\hline Content: "why" and "what-if" types of thoughts & $2.73(.90)$ & $2.79(1.02)$ & $2.74(.84)$ \\
Content: thoughts related to stress event & $3.20(.70)$ & $3.13(.81)$ & $3.11(.68)$ \\
Content: depressive thoughts & $2.93(.84)$ & $3.09(.86)$ & $2.90(.81)$ \\
Intrusiveness: unproductive thoughts & $3.76(.78)$ & $3.67(.54)$ & $3.56(.53)$ \\
\hline
\end{tabular}

${ }^{1} 1=$ never; $2=$ rarely; $3=$ sometimes; $4=$ often; $5=$ always

Table 5. Relationship between intrusive memories and rumination

\begin{tabular}{lllll}
\hline & \multicolumn{3}{c}{ Participant group } & \\
\cline { 2 - 4 } & $\begin{array}{l}\text { PTSD } \\
(n=26)\end{array}$ & $\begin{array}{l}\text { Depressed with } \\
\text { trauma }(n=19)\end{array}$ & $\begin{array}{l}\text { Depressed without } \\
\text { trauma }(n=20)\end{array}$ & Statistics \\
\hline $\begin{array}{l}\text { Triggers intrusive memories } \\
\text { of traumas }\end{array}$ & & & \\
$\quad \begin{array}{l}\text { Never/sometimes } \\
\text { Often/always }\end{array}$ & $35 \%(9)^{\mathrm{a}}$ & $79 \%(15)^{\mathrm{b}}$ & - & $\chi^{2}(1)=8.476$ \\
$\begin{array}{l}\text { Stops intrusive memories } \\
\text { of traumas }\end{array}$ & $65 \%(17)^{\mathrm{a}}$ & $21 \%(4)^{\mathrm{b}}$ & - & $p=.004$ \\
$\quad \begin{array}{l}\text { Never/sometimes } \\
\text { Often/always }\end{array}$ & $96 \%(25)$ & $95 \%(18)$ & - & \\
$\begin{array}{l}\text { Triggers intrusive memories of } \\
\text { critical life events }\end{array}$ & $4 \%(1)$ & $5 \%(1)$ & - & $\chi^{2}(1)=1.316$ \\
$\quad \begin{array}{l}\text { Never/sometimes } \\
\text { Often/always }\end{array}$ & $42 \%(11)$ & $63 \%(12)$ & $65 \%(13)$ & $\chi^{2}(2)=2.966$ \\
$\begin{array}{l}\text { Stops intrusive memories of } \\
\text { critical life events }\end{array}$ & $58 \%(15)$ & $37 \%(7)$ & $35 \%(7)$ & $p=.23$ \\
$\quad \begin{array}{l}\text { Never/sometimes } \\
\text { Often/always }\end{array}$ & $96 \%(25)$ & $95 \%(18)$ & $100 \%(20)$ & $\chi^{2}(2)=.98$ \\
\hline
\end{tabular}

Note: Values with different superscripts differ significantly $(p<.05)$

often or always activated automatically and without intention [no group differences, $\chi^{2}(4)=$ $1.252, p=.921]$.

Relationship between intrusive memories and rumination. There was no difference between the groups in terms of how often rumination stopped memories of traumatic or critical life events. Furthermore, there was no difference between the groups with regard to how often rumination triggered memories of critical life events. However, concerning the overall question of how often rumination triggered intrusive memories of the trauma, the groups differed significantly. Only the PTSD group reported that rumination often or always triggered intrusive memories of traumas. These results are listed in Table 5. 


\section{Discussion}

In this study we systematically explored rumination in PTSD and in depression, with and without a traumatic experience, in an attempt to determine if there are differences in its occurrence across diagnostic groups. In line with previous research, our study confirms that rumination is common in PTSD and depression supporting the suggestion of rumination being a transdiagnostic process (Harvey et al., 2004). All participants reported ruminating on their adverse experiences (trauma and critical life events). Interestingly, as a major difference, the traumatized groups (PTSD and depressed with trauma) ruminated significantly more than the depressed without trauma group, demonstrating the impact of traumatic experiences on ruminative behaviour. A further major difference between the diagnostic groups is that in PTSD rumination seems to be a powerful trigger of intrusive images. Previous studies have indicated that intrusive memories are common in PTSD and also in depression (e.g. Brewin, Hunter et al., 1996; van der Kolk and Fisler, 1995; Michael et al., 2005b; Reynolds and Brewin, 1999; Steil and Ehlers, 2000; Mansell and Lam, 2004). A detailed investigation of the relationship between rumination and intrusive memories revealed that only the PTSD group reported that rumination often or always served as a trigger for intrusive memories. According to the rumination questionnaire, rumination seems to be a powerful internal trigger of intrusive images especially in PTSD, supporting clinical and theoretical studies on PTSD that have emphasized the remarkably wide range of external and internal triggers of re-experiencing (Brewin, Dalgleish and Joseph, 1996; Foa, Steketee and Rothbaum, 1989; Ehlers and Clark, 2000).

Rumination was rarely activated on purpose; it occurred involuntarily and was experienced as uncontrollable. This fits with the suggestion that individuals often feel compelled to ruminate, impeding adaptive problem-solving processes (Carver and Scheier, 1981; Davey, 1994). It also fits in with the results of Papageorgiou and Wells (2001) who found that patients held negative metacognitive beliefs about rumination (i.e. rumination is uncontrollable). Negative metacognitive beliefs about rumination were significantly and positively correlated with rumination and depression (Papageorgiou and Wells, 2003). A further result is that rumination in all groups reduced positive emotions and enhanced a variety of unpleasant emotions such as helplessness, anger and guilt feelings. Surprisingly, rumination did not enhance feelings of sadness or emptiness. This might be due to the circumstance that all participants were suffering from depressed mood. Hence it seems that rumination does not worsen an already established dysphoric mood. As rumination was linked to other unpleasant emotions associated with depression and reduced positive feelings, one may nevertheless say that our findings are in line with earlier results linking rumination to depression (e.g. Kuehner and Weber, 1999; McLaughlin et al., 2007; Nolen-Hoeksema, 1991; Singer and Dobson, 2007; Treynor, Gonzalez and Nolen-Hoeksema, 2003). These results suggest a possible connection to the elevated depression scores in PTSD that are often found in research (as in our study) and clinical observation.

Furthermore, our detailed investigation of thought process reveals that rumination is a complex cognitive process with different facets. The groups showed different types of thoughts such as depressive thoughts, thoughts related to the stress event, and 'why' and 'what-if' types of questions, indicating that there are different modes of rumination.

In the literature several authors have commented on different facets of thought process in rumination; the links among them are not fully understood (e.g. Trapnell and Campbell, 1999; Watkins and Moulds, 2005). Alloy et al. (2000) and Robinson and Alloy (2003), 
for example, identified another thought process in rumination after stressful life events, which they called stress-reactive rumination in an extension of Nolen-Hoeksema's (1991) concept of depressive rumination. This construct refers to an individual's tendency to dwell on negative inferences following stressful life events (Abramson, Metalsky and Alloy, 1989), as in our sample. Stress-reactive rumination seems to play an important role in the aetiology of depression (Alloy et al., 2000). Thoughts about a trauma and/or critical life event may provoke avoidance ("why" and "what if" type thoughts) that in turn exacerbates depressive thoughts. Moreover, the depressive mood state itself can increase the likelihood of ruminative thoughts by facilitating associations to negative thoughts. It can be assumed that there is a reciprocal relationship among the thought contents. Future research should clearly operationalize the type of thought content as well as components of rumination being examined (Papageorgiou and Wells, 2004; Siegle, Steinhauer, Carter and Thase, 2000).

According to our data, another similarity in rumination across the groups was a time preference for rumination. Rumination occurred especially in the afternoon and, interestingly, at night. Furthermore, we found an association between rumination and sleep problems. Rumination at night can cause or aggravate sleep problems (Harvey, 2001a; Morin and Espie, 2004). Insomnia has proven to be a common symptom in depression and PTSD and has severe consequences for the sufferer, including social, interpersonal and occupational impairment. In such cases, the insomnia is viewed as secondary to the so-called primary disorder. However, more often than not the relationship between insomnia and the other disorders is more complex than this simple distinction implies (Harvey, 2001b). Instead, the insomnia and the other disorders are typically mutually maintaining. For example, there is some support that an intervention for insomnia and nightmares for patients with PTSD not only reduces sleep complaints but also reduces the severity of PTSD symptoms (Krakow et al., 2001). Our results highlight the importance of helping patients to deal with rumination not only in daytime but also at night.

There are several limitations of the present study. For diagnostic purposes it would be helpful to use a fuller and standardized clinical interview. Our results rely on self-report data and are thus prone to retrospective memory bias. Further, the rumination questionnaire, an adapted version of the rumination interview (Michael et al., 2007), is not yet validated. Hence we cannot report its psychometric properties. Another weakness is that the sample sizes for the groups were small, although large enough to meet statistical assumption, and the method for selecting participants was not based on random assignment. Therefore there may exist a likelihood of selection biases. For example, all participants were self-referred to participate in this study. This group might represent individuals with high introspection who have less difficulty reporting their thoughts. Self-referred participants also might have fewer avoidance symptoms and emotional problems than others who refused to be involved in this study. On the other hand, it may be that people with severe emotional problems were over-represented in the present study, because they considered the study and research theme as more important and thus were more willing to participate than people with less severe problems. So in both instances there would be a restriction of range in the severity of the psychological characteristics of the participants. A further limitation that should be kept in mind is that the cross-sectional design of the study does not preclude any causal interpretations. For this purpose longitudinal studies are needed to gain more insight.

A strength of this study, however, is that it was conducted with participants from various clinical institutions who were in need of treatment, affording insight into rumination in "real" 
patients. A second strength is that a multi-method assessment for rumination was used, including a questionnaire and a log to capture participants' daily ruminative behaviour.

In conclusion, this study provides insight into the complexity of rumination and, while keeping the above-mentioned limitations in mind, suggests that rumination shares a good deal of similarity across the diagnostic groups of patients with PTSD and depressed patients with and without trauma. All participants felt compelled to ruminate, and rumination was characterized by a variety of thought contents. Rumination rarely stopped intrusive images and made all the participants feel worse. Rumination, however, always or often triggered intrusive images only in PTSD patients and, as an important difference, the traumatized individuals ruminated more than the non-traumatized depressed individuals. Furthermore, the findings support recent research on the intricate relationship between different types of intrusive cognitions.

\section{References}

Abramson, Y., Metalsky, G. I. and Alloy, L. B. (1989). Hopelessness depression: a theory-based subtype of depression. Psychological Review, 96, 358-372.

Alloy, L. B., Abramson, L. Y., Hogan, M. E., Whitehouse, W. G., Rose, D. T., Robinson, M. S., et al. (2000). The Temple-Wisconsin cognitive vulnerability to depression (CVD) project: lifetime history of Axis I psychopathology in individuals at high and low cognitive vulnerability to depression. Journal of Abnormal Psychology, 109, 403-418.

American Psychiatric Association (1994). Diagnostic and Statistical Manual of Mental Disorders (4th ed.). Washington, DC: Author.

Backhaus, K., Erichson, B., Wulff, P. and Weiber, R. (2000). Multivariate Analysemethoden: eine anwendungsorientierte Einführung. Berlin: Springer.

Beck, A. T., Steer, R. A. and Garbin, M. G. (1988). Psychometric properties of the Beck depression inventory: twenty-five years of evaluation. Clinical Psychology Review, 8, 77-100.

Beck, A. T., Ward, C. H., Mendelson, M., Mock, J. and Erbaugh, J. (1961). An inventory for measuring depression. Archives of General Psychiatry, 4, 561-571.

Behar, E., Zuellig, A. and Borkovec, T. D. (2005). Thought and imaginal activity during worry and trauma recall. Behavior Therapy, 36, 157-168.

Birrer, E., Michael, T. and Munsch, S. (2007). Intrusive images in PTSD and in traumatised and nontraumatised depressed patients: a cross-sectional clinical study. Behaviour Research and Therapy, 45, 2053-2065.

Borkovec, T. D., Ray, W. J. and Stober, J. (1998). Worry: a cognitive phenomenon intimately linked to affective, physiological, and interpersonal behavioral processes. Cognitive Therapy and Research, 22, 561-576.

Brewin, C. R. (1998). Intrusive autobiographical memories in depression and post-traumatic stress disorder. Applied Cognitive Psychology, 12, 359-370.

Brewin, C. R., Dalgleish, T. and Joseph, S. (1996). A dual representation theory of posttraumatic stress disorder and its treatment. Behaviour Research and Therapy, 39, 373-393.

Brewin, C. R., Gregory, J. D., Lipton, M. and Burgess, N. (2010). Intrusive images in psychological disorders: characteristics, neural mechanisms, and treatment implications. Psychological Review, 117, 210-232.

Brewin, C. R., Hunter, E., Carroll, F. and Tata, P. (1996). Intrusive memories in depression. Psychological Medicine, 26, 1271-1276.

Bywaters, M., Andrade, J. and Turpin, G. (2004a). Determinants of the vividness of visual imagery: the effects of delayed recall, stimulus affect and individual differences. Memory, 12, 479-488. 
Bywaters, M., Andrade, J. and Turpin, G. (2004b). Intrusive and non-intrusive memories in a nonclinical sample: the effects of mood and affect on imagery vividness. Memory, 12, 467-478.

Carlier, I. V., Voerman, B. E. and Gersons, B. P. (2000). Intrusive traumatic recollections and comorbid posttraumatic stress disorder in depressed patients. Psychosomatic Medicine, 62, 26-32.

Carver, C. S. and Scheier, M. F. (1981). Attention and Self-Regulation: a control-theory approach to human behavior. New York: Springer.

Clark, D. A. (Ed.) (2005). Intrusive Thoughts in Clinical Disorders: theory, research, treatment. New York: The Guilford Press.

Clark, D. A. and Rhyno, S. (2005). Unwanted intrusive thoughts in nonclinical individuals: implications for clinical disorders. In D. A. Clark (Ed.), Intrusive Thoughts in Clinical Disorders: theory, research, treatment (pp. 1-29). New York: The Guilford Press.

Clohessy, S. and Ehlers, A. (1999). PTSD symptoms, response to intrusive memories and coping in ambulance service workers. British Journal of Clinical Psychology, 38, 251-265.

Davey, G. C. L. (1994). Pathological worrying as exacerbated problem-solving. In G. Davey and F. Tallis (Eds.), Worrying: perspectives on theory, assessment and treatment (pp. 35-59). Chichester, UK: John Wiley and Sons Ltd.

David, D., Mellman, T. A., Mendoza, L. M., Kulick-Bell, R., Ironson, G. and Schneiderman, N. (1996). Psychiatric morbidity following Hurricane Andrew. Journal of Traumatic Stress, 9, 607-612.

Donaldson, C. and Lam, D. (2004). Rumination, mood and social problem-solving in major depression. Psychological Medicine, 34, 1309-1318.

Ehlers, A. and Clark, D. M. (2000). A cognitive model of posttraumatic stress disorder. Behaviour Research and Therapy, 38, 319-345.

Ehlers, A., Hackmann, A. and Michael, T. (2004). Intrusive re-experiencing in post-traumatic stress disorder: phenomenology, theory, and therapy. Memory, 12, 403-415.

Ehlers, A., Mayou, R. A. and Bryant, B. (1998). Psychological predictors of chronic posttraumatic stress disorder after motor vehicle accidents. Journal of Abnormal Psychology, 107, 508-519.

Foa, E. B. (1995). The Posttraumatic Diagnostic Scale (PDS) manual. Minneapolis, MN: National Computer Systems.

Foa, E. B., Cashman, L., Jaycox, L. and Perry, K. (1997). The validation of a self-report measure of posttraumatic stress disorder: the posttraumatic diagnostic scale. Psychological Assessment, 9, 445451.

Foa, E. B. and Kozak, M. J. (1986). Emotional processing and fear: exposure to corrective information. Psychological Bulletin, 99, 20-35.

Foa, E. B., Steketee, G. and Rothbaum, B. O. (1989). Behavioural/cognitive conceptualisation of post-traumatic stress disorder. Behaviour Therapy, 20, 155-176.

Fresco, D. M., Frankel, A. N., Mennin, D. S., Turk, C. L and Heimberg, R. G. (2002). Distinct and overlapping features of rumination and worry: the relationship of cognitive production to negative affect states. Cognitive Therapy and Research, 26, 179-188.

Harvey, A. G. (2001a). I can't sleep, my mind is racing! An investigation of strategies of thought control in insomnia. Behavioural and Cognitive Psychotherapy, 29, 3-12.

Harvey, A. G. (2001b). Insomnia: symptom or diagnosis? Clinical Psychology Review, 21, 1037-1059.

Harvey, A. G., Watkins, E., Mansell, W. and Shafran, R. (2004). Cognitive Behavioural Processes Across Psychological Disorders: a transdiagnostic approach to research and treatment. Oxford: Oxford University Press.

Hayes, S. C., Luoma, J. B., Bond, F. W., Masuda, A. and Lillis, J. (2006). Acceptance and commitment therapy: model, processes and outcomes. Behaviour Research and Therapy, 44, 1-25.

Hayes, S. C., Strosahl, K. and Wilson, K. G. (1999). Acceptance and Commitment Therapy: an experiential approach to behaviour change. New York: Guilford.

Holmes, E. A. and Hackmann, A. (Eds.) (2004). Special issue on mental imagery and memory in psychopathology. Memory, 12 . 
Hong, R. Y. (2007). Worry and rumination: differential associations with anxious and depressive symptoms and coping behaviour. Behaviour Research and Therapy, 45, 277-290.

Kolk, B. A., Van, Der and Fisler, R. (1995). Dissociation and the fragmentary nature of traumatic memories: overview and exploratory study. Journal of Traumatic Stress, 8, 505-525.

Krakow, B., Johnston, L., Melendrez, D., Hollifield, M., Warner, T. D., Chavez-Kennedy, D., et al. (2001). An open-label trial of evidence-based cognitive behavior therapy for nightmares and insomnia in crime victims with PTSD. American Journal of Psychiatry, 158, 2043-2047.

Kuehner, C. and Weber, I. (1999). Responses to depression in unipolar depressed patients: an investigation of Nolen-Hoeksema's response styles. Theory Psychological Medicine, 29, 13231333.

Kuyken, W. and Brewin, C. R. (1994). Intrusive memories of childhood abuse during depressive episodes. Behaviour Research and Therapy, 32, 525-528.

Lavender, A. and Watkins, E. (2004). Rumination and future thinking in depression. British Journal of Clinical Psychology, 43, 129-142.

Lehmann, E. L. (1998). Nonparametrics: statistical methods based on ranks. Englewood Cliffs, NJ: Prentice Hall.

Maercker, A., Michael, T., Fehm, L., Becker, E. S. and Margraf, J. (2004). Age of traumatisation as a predictor of post-traumatic stress disorder or major depression in young women. British Journal of Psychiatry, 184, 482-487.

Maes, M., Mylle, J., Delmeire, L. and Altamura, C. (2000). Psychiatric morbidity and comorbidity following accidental man-made traumatic events: incidence and risk factors. European Archives of Psychiatry and Clinical Neuroscience, 250, 156-162.

Mansell, W. and Lam, D. (2004). A preliminary study of autobiographical memory in remitted bipolar and unipolar depression. Memory, 12, 437-446.

McLaughlin, K. A., Borkovec, T. D. and Sibrava, N. (2007). The effects of worry and rumination on affect states and cognitive activity. Behavior Therapy, 38, 23-38.

Michael, T. and Ehlers, A. (2007). Enhanced priming for trauma-related stimuli and posttraumatic stress disorder symptoms: two experimental investigations. Behaviour Research and Therapy, 45, 341-358. 77

Michael, T., Ehlers, A. and Halligan, S. L. (2005a). Enhanced priming for trauma-related material in posttraumatic stress disorder. Emotion, 5, 103-112

Michael, T., Ehlers, A., Halligan, S. L. and Clark, D. M. (2005b). Unwanted memories of assault: what intrusion characteristics are associated with PTSD? Behaviour Research and Therapy, 43, 613628.

Michael, T., Halligan, S. L., Clark, D. M. and Ehlers, A. (2007). Rumination in posttraumatic stress disorder. Depression and Anxiety, 24, 307-317.

Morin, C. M. and Espie, C. A. (2004). Insomnia: psychological assessment and management. New York: Guilford Press.

Muris, P., Roelofs, J., Meesters, C. and Boomsma, P. (2004). Rumination and worry in nonclinical adolescents. Cognitive Therapy and Research, 28, 539-554.

Murray, J., Ehlers, A. and Mayou, R. A. (2002). Dissociation and post-traumatic stress disorder: two prospective studies of road traffic accident survivors. British Journal of Psychiatry, 180, 363-368.

Nolen-Hoeksema, S. (1991). Responses to depression and their effects on the duration of depressive episodes. Journal of Abnormal Psychology, 100, 569-582.

Nolen-Hoeksema, S. (2000). The role of rumination in depressive disorders and mixed anxiety/depressive symptoms. Journal of Abnormal Psychology, 109, 504-511.

Nolen-Hoeksema, S., Parker, L. E. and Larson, J. (1994). Ruminative coping with depressed mood following loss. Journal of Personality and Social Psychology, 67, 92-104.

Papageorgiou, C. and Wells, A. (2001). Metacognitive beliefs about rumination in recurrent major depression. Cognitive and Behavioral Practice, 8, 160-164. 
Papageorgiou, C. and Wells, A. (2003). An empirical test of a clinical meta-cognitive model of rumination and depression. Cognitive Therapy and Research, 27, 261-273.

Papageorgiou, C. and Wells, A. (2004). Nature, functions, and beliefs about depressive rumination. In C. Papageorgiou and A. Wells (Eds.), Depressive Rumination: nature, theory and treatment (pp. 3-20). Chichester: Wiley.

Reynolds, M. and Brewin, C. R. (1999). Intrusive memories in depression and posttraumatic stress disorder. Behaviour Research and Therapy, 37, 201-215.

Robinson, S. M. and Alloy, L. B. (2003). Negative cognitive styles and stress-reactive rumination interact to predict depression: a prospective study. Cognitive Therapy and Research, 27, 275-291.

Roemer, L. and Borkovec, T. D. (1993). Worry: unwanted cognitive activity that controls unwanted somatic experience. In D. M. Wegner and J. W. Pennebaker (Eds.), Handbook of Mental Control. Englewood Cliffs, NJ: Prentice Hall.

Schwarzer, R. and Schulz, U. (2002). The role of stressful life events. In A. M. Nezu, C. M. Nezu and P. A. Geller (Eds.), Comprehensive Handbook of Psychology, Vol. 9: health psychology (pp. 27-49). New York: Wiley.

Segal, Z. V., Williams, J. M. G. and Teasdale, J. D. (2002). Mindfulness-Based Cognitive Therapy Depression. New York: Guilford.

Segerstrom, S. C., Tsao, J. C., Alden, L. E. and Craske, M. G. (2000). Worry and rumination: repetitive thought as a concomitant and predictor of negative mood. Cognitive Therapy and Research, 24, 671-688.

Siegle, G. J., Steinhauer, S., Carter, C. S. and Thase, M. E. (2000). Convergence and Divergence in Measures of Rumination. Paper presented at the $34^{\text {th }}$ annual convention of the Association for Advancement of Behaviour Therapy, New Orleans. Retrieved on 21 January 2007 from http://kraepelin.wpic.pitt.edu/ siegle/gregweb/aabt00/

Singer, A. R. and Dobson, K. S. (2007). An experimental investigation of the cognitive vulnerability to depression. Behaviour Research and Therapy, 45, 563-575.

Steil, R. and Ehlers, A. (2000). Dysfunctional meaning of posttraumatic intrusions in chronic PTSD. Behaviour Research and Therapy, 38, 537-558.

Teasdale, D. T. (1999). Emotional processing, three modes of mind and the prevention of relapse in depression. Behaviour Research and Therapy, 37, 53-77.

Trapnell, P. D. and Campbell, J. D. (1999). Private self-consciousness and the five-factor model of personality: distinguishing rumination from reflection. Journal of Personality and Social Psychology, 76, 284-304.

Treynor, W., Gonzalez, R. and Nolen-Hoeksema, S. (2003). Rumination reconsidered: a psychometric analysis. Cognitive Therapy and Research, 27, 247-259.

Watkins, E. (2004). Appraisals and strategies associated with rumination and worry. Personality and Individual Differences, 37, 679-694.

Watkins, E. and Moulds, M. (2005). Distinct modes of ruminative self-focus: impact of abstract versus concrete rumination on problem solving in depression. Emotion, 5, 319-328.

Watkins, E. and Teasdale, J. D. (2001). Rumination and overgeneral memory in depression: effects of self-focus and analytical thinking. Journal of Abnormal Psychology, 110, 353-357.

Watkins, E., Teasdale, J. D. and Williams, R. M. (2000). Decentring and distraction reduce overgeneral autobiographical memory in depression. Psychological Medicine, 30, 911-920.

Wells, A. (2000). Emotional Disorders and Metacognition: innovative cognitive therapy. Chichester, UK: Wiley.

Wells, A. and Papageorgiou, C. (2004). Metacognitive therapy for depressive rumination. In C. Papageorgiou and A. Wells (Eds.), Depressive Rumination: nature, theory and treatment (pp. 259273). Chichester, UK: Wiley.

Wells, A. and Sembi, S. (2004). Metacognitive therapy for PTSD: a core treatment manual. Cognitive and Behavioural Practice, 11, 365-377. 
Zetsche, U., Ehring, T. and Ehlers, A. (2009). The effects of rumination on mood and intrusive memories after exposures to traumatic material: an experimental study. Journal of Behavior Therapy and Experimental Psychiatry, 40, 499-514.

Zimmerman, M. and Coryell, W. (1987a). The inventory to diagnose depression: lifetime version. Acta Psychiatrica Scandinavica, 75, 495-499.

Zimmerman, M. and Coryell, W. (1987b). The inventory to diagnose depression (IDD): a self-report scale to diagnose major depressive disorder. Journal of Consulting and Clinical Psychology, 55, $55-59$.

Zimmerman, M. and Coryell, W. (1988). The validity of a self report questionnaire for diagnosing major depressive disorder. Archives of General Psychiatry, 45, 738-740.

Zimmermann, M., Coryell, W., Corenthal, C. and Wilson, S. (1986). A self-report scale to diagnose major depressive disorder. Archives of General Psychiatry, 43, 1076-1081.

Zimmerman, M., Sheeran, T. and Young, D. (2004). The diagnostic inventory for depression: a selfreport scale to diagnose DSM-IV major depressive disorder. Journal of Clinical Psychology, 60, 87-110.

\section{Appendix: Aggregation of rumination questionnaire}

\section{(1) Occurrence of rumination}

Answer: Yes/No

(1a) Rumination revolves about the trauma

(1b) Rumination revolves about other critical life events

(2) Content and frequency of rumination

Answer: Never/Rarely/Sometimes/Often/Always

(2a) "Why" and "what-if" type thoughts:

- About what I would like to say or do to the perpetrator

- About how unfair the experience is

- About what I could have done differently before the trauma happened

- About what I could have done differently before the negative life event happened

- About the trauma having destroyed my life

- About the negative life event having destroyed my life

(2b) Depressive thoughts:

- About the insults I have experienced up to now

- About how bad I am

- About how threatening the world is

- About my wrong decisions

- About my incompetence

- About my bad relationships to other people

- About never being able to trust anybody anymore

(2c) Thoughts related to the stress event:

- About how I felt while I was experiencing the trauma

- About how I felt while I was experiencing the negative life event

- About what I thought while I was experiencing the trauma

- About what I thought while I was experiencing the negative life event

- About the long-term consequences of the trauma

- About the worst part of the traumatic experience

- About the worst part of the negative life event 


\section{(3) Level of intrusiveness of rumination}

Answer: Never/Rarely/Sometimes/Often/Always

(3a) 'I dwell automatically'; 'I start to dwell on purpose'

(3b) Unproductive thoughts:

- I am at the mercy of rumination

- I find it hard to put a stop to them

- The thoughts get more and more gloomy

- I seem to be pushed from one topic to the next

(4) Relationship between rumination and intrusive images

Answer: Never/Rarely/Sometimes/Often/Always

(4a) Rumination triggers intrusive memories of the trauma/ of critical life event

(4b) Rumination stops intrusive memories of the trauma/of critical life event 